\title{
Advances in Surface Engineering Using TIG Processing to Incorporate Ceramic Particulates into Low Alloy and Microalloyed Steels - A Review
}

\author{
Patricia Muñoz-Escalona ${ }^{*}$, Shahjahan Mridha ${ }^{2}$, Thomas Neville Baker ${ }^{2}$ \\ ${ }^{1}$ Department of Mechanical Engineering, Glasgow Caledonian University, Glasgow G4 OBA, UK \\ 2 Department of Mechanical and Aerospace Engineering, University of Strathclyde, Glasgow G1 1XJ, UK \\ * Corresponding author's e-mail: patricia.munoz@gcu.ac.uk
}

\begin{abstract}
The application of surface engineering techniques to improve the surface properties of carbon steels using high powered lasers for transformation hardening and surface melting is well established. Based on this previous research, a tungsten inert gas torch (TIG) technique has more recently been explored for the surface modification of steels, as a much cheaper option to lasers. In the present research, initial studies compared the preheat temperature recorded on a low alloy steel with $\mathrm{Ar}, \mathrm{He}$ and $\mathrm{N}$ protective shielding gases over a single track length. The effect of overlapping 17 tracks on the temperature variation for three different gases was also explored. These studies lead to Ar being the chosen gas for the next stages of the work. During TIG processing, incorporation of fine TiC or $\mathrm{SiC}$ ceramic particulates into the liquid steel was investigated, with the aim of obtaining a uniformly high hardness in a crack and porous- free melt zone of sufficient length and depth to provide improved wear resistance over the parent steel. TiC particulates of 45-100 $\mu \mathrm{m}$ size were preplaced on a low alloy steel, and following TIG processing, the hardness increased from the as-received steel value of $\sim 200 \mathrm{Hv}$ to $\sim 800 \mathrm{Hv}$, due to some dissolution and re-precipitation of TiC particulates. The incorporation of the more economic SiC particulates of $\sim 5 \mu \mathrm{m}$ or $\sim 75 \mu \mathrm{m}$ size preplaced on a microalloyed steel was investigated. Single track surface zones were melted by a tungsten inert gas torch, and the effect of two energy inputs, 420 and $840 \mathrm{Jmm}^{-1}$, compared. The results showed that the samples melted using $420 \mathrm{Jmm}^{-1}$ were crack-free. Analytical microstructural and XRD studies established that both sizes of $\mathrm{SiC}$ particulates dissolved, and that some of the hardness increase recorded was due to formation of a high carbon martensite. A potential method of decreasing $\mathrm{SiC}$ particulate dissolution by generating a high $\mathrm{Fe}-\mathrm{Si}$ liquid, thereby retaining the ceramic in the microalloyed steel after processing, was found to show promise.
\end{abstract}

Keywords: microstructure, microhardness, steels, surface engineering, TIG melting, preheat, carbide particulates.

\section{INTRODUCTION}

This paper is an invited review of the work undertaken by the present authors and their colleagues listed in the references, using surface engineering to enhance the surface properties of low alloy and microalloyed steels through the addition of ceramic powders.

The background to the present projects emanated from work on particulate metal matrix composities (MMC's), which in the 1960's, grew from the development of cermets, at that time a new generation of composite materials designed to have optimal properties, including high temperature resistance and the hardness of a ceramic combined with the ability to undergo plastic deformation like a metal. Generally, the metallic elements used as a binder were nickel, molybdenum, and cobalt, and while cermets, comprised by volume $<20 \%$ metal, MMC's normally have $\geq 80 \%$ of metal. Both can be manufactured by a sintering process $[1,2]$. A more recent version of cermets are MAX phases, some comprising ternary carbides and nitrides of aluminium or titanium alloys $[3,4]$. 
The results of the current research are placed in the context of comparable work in the literature. The present projects grew out of previous research on bulk aluminium metal matrix composites. In the first of three examples, Song and Baker [5] found a significant acceleration of ageing of an aluminium MMC comprising AA6061 with either $15 \mathrm{vol} . \%$ of $7 \mu \mathrm{m} \mathrm{SiC}$ powder or 15 vol. $\%$ Saffil, $\delta \mathrm{Al}_{2} \mathrm{O}_{3}$, both of which recorded higher dislocation densities than the alloy, resulting in dislocation assisted nucleation processes reducing the apparent activation energy for nucleation in the MMCs.

The abrasive wear behaviour recorded through pin on disc testing of aluminium alloy AA6061 were compared by Gurcan and Baker [6] with that of AA6061 MMC's, including one with 60 vol. $\% \mathrm{SiC}$ and a second, a hybrid containing $11 \mathrm{vol} \%$ Saffil $+20 \mathrm{vol} . \% \mathrm{SiC}$. All the materials were all in the T6 condition. Both the MMC's showed significant improvements in wear resistance compared to the alloy.

Zhang et al. [7] investigated the hot deformation behaviour in the T4 condition of the aluminium alloy AA6061 and that of AA6061 plus $20 \mathrm{vol} . \% \mathrm{SiC}$ powder in the temperature range $573 \mathrm{~K}$ to $773 \mathrm{~K}$ and at strain rates of $0.005,0.05$ and $0.09 \mathrm{~s}^{-1}$. The different activation energies determined for both specimens was explained by the occurrence of dynamic precipitation and coarsening during deformation as a function of the experimental conditions.

Modifications in microhardness and microstructure in aluminium MMC's [8-12] and titanium MMC's $[8,13-16]$ resulting from surface engineering using a $5 \mathrm{~kW}$ continuous $\mathrm{CO}_{2}$ laser were studied in detail. The sliding wear resistance after testing AA6061 injected with $150 \mu \mathrm{m}$ $\mathrm{SiC}$ particulate was found to be slightly inferior to that of AA6061 preplaced with $45 \mu \mathrm{m} \mathrm{SiC}$ particulate [9]. An extension of this research by $\mathrm{Hu}$ and Baker [10] studying MMC's based on both AA6061 and AA8090 with $6.5 \mu \mathrm{m} \mathrm{SiC}$ particulates, found from analytical TEM, that the $\mathrm{SiC}$ dissolved and re-precipitated $\mathrm{as}_{4} \mathrm{AiC}_{4}$ and $\mathrm{Al}_{4} \mathrm{C}_{3}$ during single track laser processing. This was followed by an examination of the formation of continuous surface Al-SiCp metal matrix composites by overlapping laser tracks [11]. Here it was found that using a laser power input of $100-200 \mathrm{MJm}^{-2} \mathrm{Al}_{4} \mathrm{C}_{3}$ precipitated, whereas with $560 \mathrm{MJm}^{-2}, \mathrm{Al}_{4} \mathrm{SiC}_{4}$ was more likely to form.
A previously unreported hexagonal AlSiC phase was also present at the high energy input [12].

Research on laser surface engineering of $\mathrm{CP}$ Titanium and Ti6A14V (IMI318) alloys also employed a $5 \mathrm{~kW}$ continuous $\mathrm{CO}_{2}$ laser. Mridha and Baker [13] aimed to develop surface MMC's to increase the $350 \mathrm{Hv}$ base hardness of IMI318 titanium alloy, by preplacing $10 \mathrm{wt} . \% \mathrm{SiC}$ powder onto the surface and then laser processing under nitrogen. Close to the surface, the hardness was found to increase to $1400 \mathrm{Hv}$, which then decreased to $600 \mathrm{Hv}$ at a depth of $\sim 1 \mathrm{~mm}$. As in the case of the aluminium alloys, SiC particulates dissolved, and here were replaced by TiN dendrites growing from the surface togtrher with a threadlike microstructural constituent down through the melt zone. This fine microstructure, also present when the base alloy CPTi [14] was identified using X-ray diffraction combined with TEM as $\mathrm{Ti}_{5} \mathrm{Si}_{3}[15]$. The laser surface modification of titanium alloys has been reviewed [16], presenting a fuller account. This followed the pioneering work of Ayers [17], West [18], Bergmann and Mordike [19] and Bell et al. [20].

The extension of this research, with the objective of improving the surface properties of steels, also involved a change from using lasers to a tungsten inert gas torch, a significantly more economic process [21-25].

In the work by the present authors presented in nine papers [26-34], the TIG processing conditions used similar to those shown to be suitable by others $[35,36]$. The system first chosen to explore these features was that of a low alloy steel, initially TIG processed to incorporate $\mathrm{TiC}$ particulates $[26,27]$. This produced an increase of up to four times the hardness of the steel. Next, Patel et al. [26] using a microalloyed steel plate, substituted $\sim 5 \mu \mathrm{m} \mathrm{SiC}$ for the TiC particulates, with the aim of dissolving the ceramic during processing, and precipitating new phases as a fine dispersion on cooling, as found for Al based MMC's [8-12], Both $\mathrm{Ar}$ and $\mathrm{Ar}+\mathrm{He}$ shielding gases with 420, 530 or $840 \mathrm{Jmm}^{-1}$ TIG energy inputs were investigated. After processing, a hardness of up to $1000 \mathrm{Hv}$ was recorded [28].

Following the work of Patel et al [26], subsequent studies investigated the effect of different protective shielding gases, energy input, melt zone shape and dimensions, microhardness variations and resultant microstructure, using either $\sim 5$ $\mu \mathrm{m}$ or $\sim 75 \mu \mathrm{m} \mathrm{SiC} \mathrm{particulates.} \mathrm{The} \sim 5 \mu \mathrm{m} \mathrm{SiC}$ was expected to fully dissolve, nucleating new 
phases during cooling. On the other hand, the $\sim 75$ $\mu \mathrm{m} \mathrm{SiC}$ would be expected to show only partial dissolution, and the microstructure also benefiting from nucleation of new phases [28-34] A feature of much of this work was the examination of variations in temperature along the TIG melted track, plus in some experiments, along different tracks which were overlapped to treat an area of the parent plate $[27,28]$.

\section{EXPERIMENTAL}

A surface engineering technique based on a tungsten inert gas (TIG) torch was used initially to study the influence of overlapping tracks on a low alloy (LA) steel (BM) with a composition of $\quad 0.43 \mathrm{C}-0.57 \mathrm{Mn}-0.30 \mathrm{Si}-0.04 \mathrm{~S}-0.035 \mathrm{P}-1.15 \mathrm{Cr}-$ $2.57 \mathrm{Ni}-0.63 \mathrm{Mo}$, bal.Fe (wt.\%) incorporating 45 $100 \mu \mathrm{m}, 99.5 \%$ purity $\mathrm{TiC}$ particulates. In the first project, 17 tracks, overlapped by $50 \%$, were melted on the BM steel $(100 \times 40 \times 15 \mathrm{~mm})$ with an energy input of $1344 \mathrm{Jmm}^{-1}$ protected by an $\mathrm{Ar}$, flowing at $20 \mathrm{Lmin}^{-1}$. Four thermocouples were placed, (T1) BM, (T2) track no. 3, (T3) track no. 9 and (T4) track no. 17, to record the temperatures during melting and cooling [27].

Figure 1 shows schematic drawings which give the track section dimensions and positions of thermocouples (a) of the BM LA steel used for TIG processing incorporating TiC particulates, (b) of the BM MA steel incorporating $\sim 5 \mu \mathrm{m}$ or $\sim 75 \mu \mathrm{m} \mathrm{SiC} \mathrm{particulates} \mathrm{[26,} \mathrm{33,} \mathrm{34].}$

Figure 1(b) shows in black the four sections of melt track and the melting direction. Both figures show that the thermocouples, which recorded temperature increases associated with preheat [35], were positioned $5 \mathrm{~mm}$ below the BM surface. This distance was chosen at the start of the research to

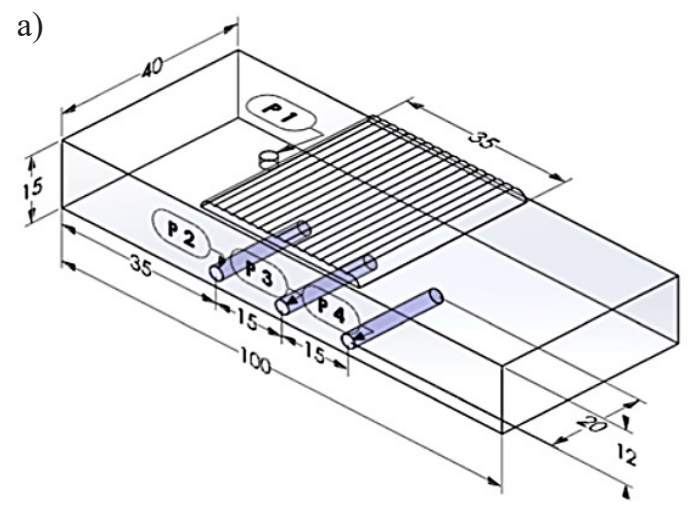

avoid the MZ liquid coming into contact with the thermocouples during TIG processing.

A second project examined the influence of $\mathrm{SiC}$ powder on the melt zone dimensions, microhardness variations, microstructure and phase determination of a processed $\mathrm{Nb}$ - $\mathrm{Ti}$ microalloyed (MA) steel. Furthermore, these features were considered in different places along the re-solidified track, Figure 1(b) to explore the importance of preheat [33].

The composition of the MA steel base metal (BM), $\quad 0.14 \mathrm{C}-1.26 \mathrm{Mn}-0.32 \mathrm{Si}-0.004 \mathrm{~S}-0.015 \mathrm{P}-$ $0.012 \mathrm{Cr}-0.002 \mathrm{Mo}-0.007 \mathrm{Ni}-0.02 \mathrm{Cu}-0.028 \mathrm{Al}$ $-0.037 \mathrm{Nb}-0.008 \mathrm{Ti}-0.001 \mathrm{~V}$,bal.Fe (wt.\%) was determined using a Glow Discharge Optical Emission Spectrometer (GDES), model Horiba GDOES profilometer.

A Miller Dynastry 300DX TIG equipment was used in all the projects to generate an arc with a $2.4 \mathrm{~mm}$ diameter thoriated tungsten electrode. The electrode was direct current negative and the tip of the order $1 \mathrm{~mm}$ above the specimen surface to guarantee a constant energy input (E). Energy inputs in the range 210 to $1344 \mathrm{Jmm}^{-1}$ were used over the course of the work [26-33].

Specimens were prepared for metallographic analysis following ASTM E3-01 standards. The crystallographic characterization of phases developed in the re-solidified surface was obtained by X-ray diffraction, which was carried out in a Bruker D8 Advance with Da Vinci. A $\mathrm{Cu}(\lambda=$ $1.5406 \AA$ ) source X-ray tube was used. The Xray tube was set to $40 \mathrm{kV}$ and $40 \mathrm{~mA}$, the step size to 0.5 seconds and the increment, $0.02^{\circ}$. The 2-theta range measured was $20-100^{\circ}$. XRD data from all these sources was characterized using the International Centre for Diffraction Data (ICDD) PDF-2 database incorporated in the Bruker D8

b)

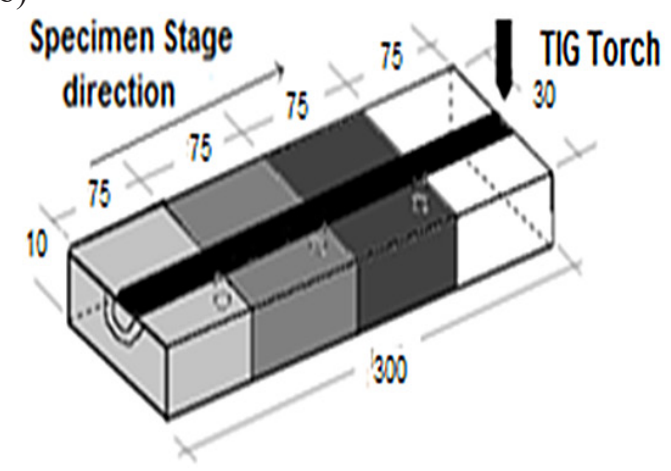

Fig. 1. a) Schematic drawing of overlapping tracks and b) Schematic drawing of single track 
Advance with Da Vinci XRD equipment. This also allowed indexing the peaks.

Microhardness measurements were conducted following the procedures detailed in BS 1043-2 1993 and BS6507-1 1998, using a Mitutoyo MVK G1 microhardness tester with $200 \mathrm{gf}$ load and a $15 \mathrm{~s}$ delay. Readings were taken on the specimen cross-section, of the melt zone (MZ), the heat affected zone (HAZ) and the BM, starting at $0.1 \mathrm{~mm}$ from the melt zone edge and taking measurements in a vertical distance at $0.2 \mathrm{~mm}$ apart, towards the centre of the BM.

\section{RESULTS AND DISCUSSION}

An increase in temperature occurs in the tracks as processing proceeds, through heat transfer by conduction, which is described as the preheat [35]. This can have a significant influence on the maximium temperature reached during the processing, and the subsequent rate of cooling, both which influence final the microstructure and properties of the solidified MZ.

A preliminary mathematical model [32] based on the Rosenthal approach [36] used often for modelling welding situations, was developed to predict the temperature at any point in space/time. Based on the increase in temperature (preheat) between the region close to the start of the track resulting from TIG processing and that close to the end of the track in the case of single track melting, Figure 2, shows a satisfactory agreement between experimental and numerical values obtained from the model [32].
A more pronounced effect has been recorded when laser or TIG processing is used to modify an area of the surface by undertaking a series of tracks, involving overlapping them usually in the range 30$50 \%$ [27, 28]. Figure 3(a) shows the effect of preheat during TIG processing 13 tracks at an energy imput of $1344 \mathrm{Jmm}^{-1}$. The temperature increased from $230{ }^{\circ} \mathrm{C}$ at track 1 to $>700{ }^{\circ} \mathrm{C}$ at track 13 , a level similar to that noted by $\mathrm{Hu}$ and Baker [35] during laser nitriding of a Ti-6Al-4V alloy.

The results obtained by Mridha and Baker [27] and Mridha et al. [28] employing TIG processing to modify the melt zone microstructure and microhardness of microalloyed steel through the incorporation of $\mathrm{TiC}$ particulates were in agreement with other work [24, 25, 29]. The microhardness of the BM steel was $\sim 200$ Hv. A microhardness map taking into account all 13 tracks at six depths through the MZ determined after TIG processing, showed that a maximum of $\sim 800 \mathrm{Hv}$ was recorded in tracks 4-6, due to undissolved, and dissolved and reprecipitated TiC. For tracks 11-13, the microhardness was lower at $\sim 700 \mathrm{Hv}$, as the cooling rate became a dominating factor [27].

The properties of the gas such as specific heat, thermal conductivity and ionization potential, used for protecting the steel during TIG or laser processing, can have a significant effect on the maximum preheat temperature and cooling rate, both of which affect the final microstructure. This was the subject considered in three papers [26, 28, 29]. Initial studies by Patel et al., [26] replaced the significantly more expensive $\mathrm{TiC}$ particulates by $\mathrm{SiC}$ particulates, and compared the effect of two shielding gases, $100 \% \mathrm{Ar}$ and $80 \% \mathrm{Ar} 20 \% \mathrm{He}$ after TIG processing at energy

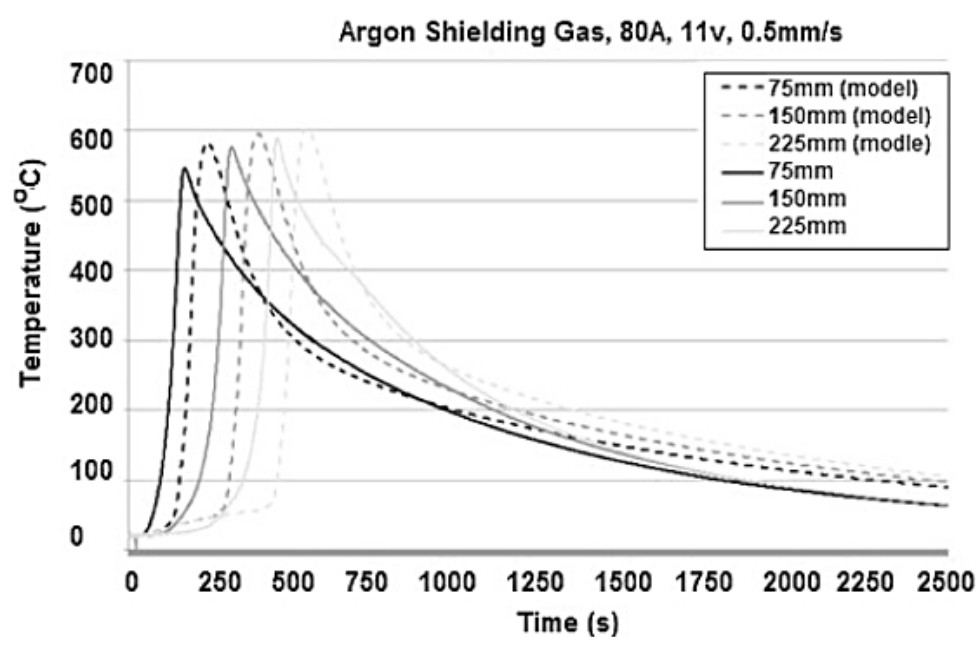

Fig. 2. Comparison between experimental and numerical values 

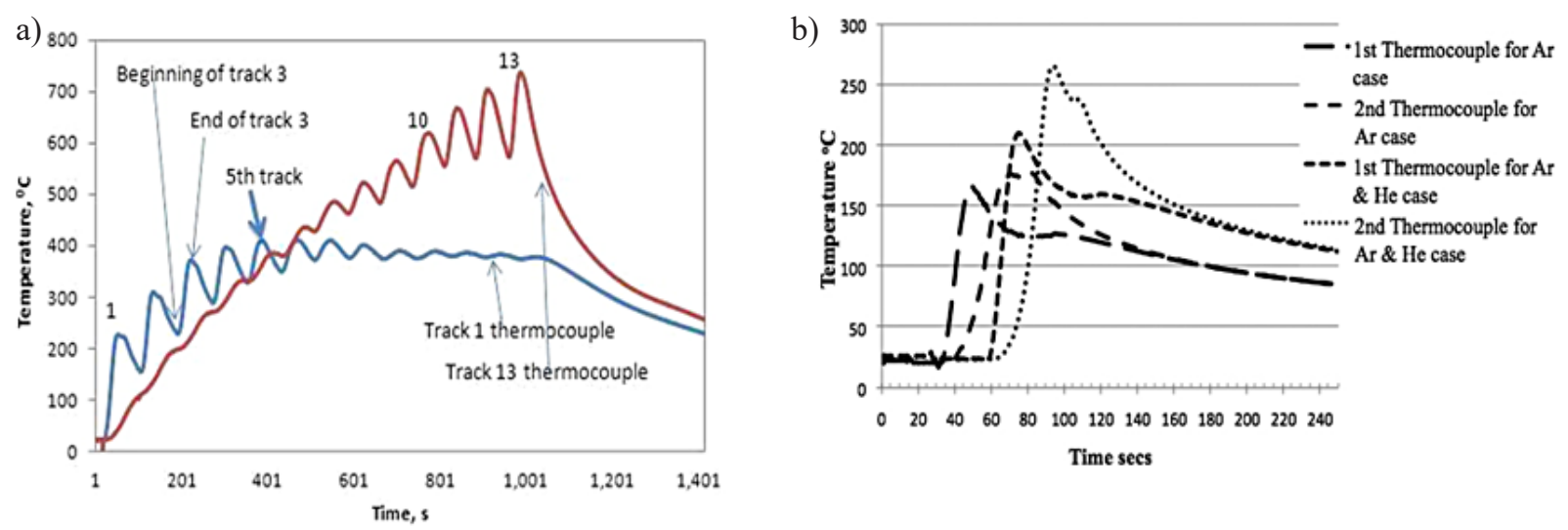

Fig. 3. a) Graph of temperature vs time recorded by thermocouples for tracks 1 and 13. and b) Graph of temperature vs time recorded by thermocouples for two sections of a single track shielded by $\mathrm{Ar}$ or $\mathrm{Ar}+\mathrm{He}$

inputs of $420 \mathrm{Jmm}^{-1}, 530 \mathrm{Jmm}^{-1}$ and $840 \mathrm{Jmm}^{-1}$ on the solidified melt depth dimensions and the microhardness of a microalloyed steel, with and without $\mathrm{SiC}$ particulate additions. The MA steel specimen given a coating of $10 \mathrm{wt} \% \mathrm{SiC}$ and processed at 530 $\mathrm{Jmm}^{-1}$ recorded the highest temperature in both locations and under both environments. These conditions resulted in a microstructure similar to that of a silicon white cast iron.

An extension of this work [29] considered TIG processing of the BM steel alone, in the range 210 $\mathrm{Jmm}^{-1}$ to $840 \mathrm{Jmm}^{-1}$ protected by three shielding gases, $\mathrm{Ar}, \mathrm{He}$ and N, Figure 4. The specimen was again studied in four sections, as shown in Figure 1(b).
The influence of shielding gas on the melt zone depth, surface roughness, macrostructure and microhardness were also considered. The melt zone cross sections, Figure 4, at three distances along the MZ track after processing at $840 \mathrm{Jmm}^{-1}$ show the effect of shielding gas on the dimensions of the $\mathrm{MZ}$ and the variation in the macrostructure [29]. Progressively greater width and depth are seen in Table 1 between Ar, $\mathrm{N}$ and $\mathrm{He}$, while Table 2 shows little change in MZ and HAZ microhardness between $\mathrm{Ar}$ and $\mathrm{He}$, but higher values for $\mathrm{N}$.

Figure 4 also shows that a much coarser macrostructure is developed under $\mathrm{He}$ and $\mathrm{N}$ shielding gases, and that the surface roughness in these

Table 1. Dimensions of the fusion zone at different distances from the sample's edge

\begin{tabular}{|l|c|c|c|c|c|c|}
\hline \multirow{2}{*}{ Shielding gas } & \multicolumn{3}{|c|}{ Width } & \multicolumn{3}{c|}{ Depth } \\
\cline { 2 - 7 } & $75 \mathrm{~mm}$ & $150 \mathrm{~mm}$ & $225 \mathrm{~mm}$ & $75 \mathrm{~mm}$ & $150 \mathrm{~mm}$ & $225 \mathrm{~mm}$ \\
\hline Argon & 3.7 & 3.9 & 3.9 & 1.8 & 2.1 & 2.1 \\
\hline Nitrogen & 6.1 & 7.1 & 7.9 & 1.7 & 2.6 & 3.2 \\
\hline Helium & 7.3 & 7.3 & 7.5 & 3.6 & 3.6 & 3.9 \\
\hline
\end{tabular}

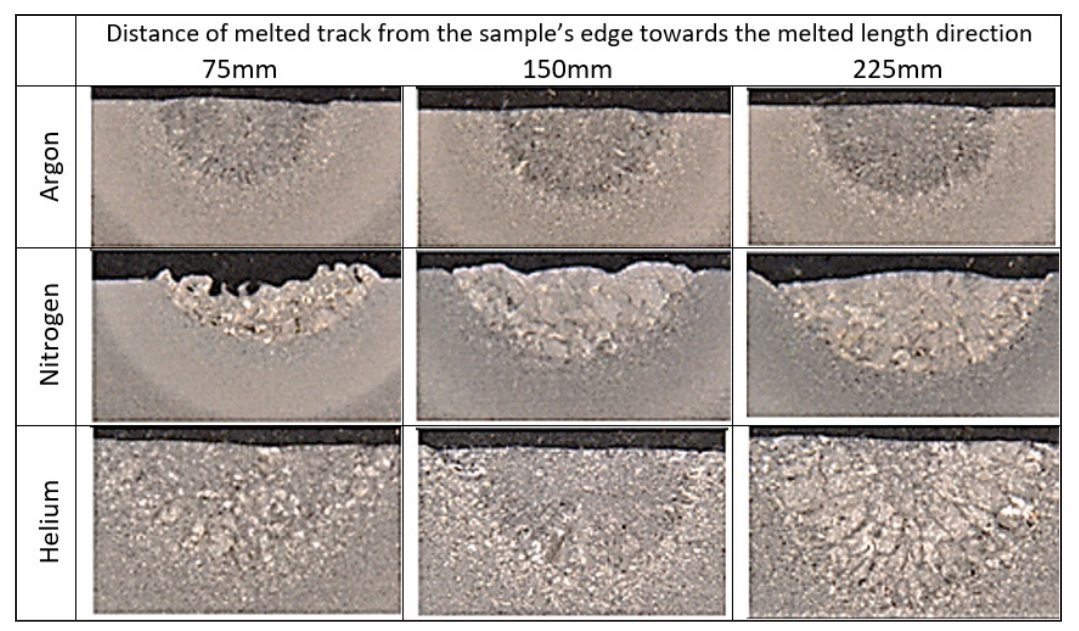

Fig. 4. The variation in the $M Z$ cross section at three positions along the track for three gases 
Table 2. Average Vickers hardness (HV) of the melted track

\begin{tabular}{|c|c|c|c|}
\hline \multirow{2}{*}{ Shielding gas } & Melt zone & HAZ & Parent material \\
\cline { 2 - 4 } & \multicolumn{3}{|c|}{$(\mathrm{HV})$} \\
\hline Argon & 164 & 160 & 153 \\
\hline Nitrogen & 220 & 190 & 150 \\
\hline Helium & 160 & 157 & 150 \\
\hline
\end{tabular}

cases was significantly greater than using Ar. Both these observations were important in choosing Ar for the next stage of the research.

This stage involved expanding the work of Patel et al. [26] by considering the effect on microhardness and microstructure through the incorporation of $\mathrm{SiC}$ particulates in an MA steel plate by TIG processing using energy inputs of $420 \mathrm{Jmm}^{-1}$ or $840 \mathrm{Jmm}^{-1}$, with Ar as a shielding gas $[30,33,34]$. The dimensions and thermocouple positions in the MA steel plate was as shown in Figure 1(b). Hardness profiles from indents made in the centre of the MZ, shown in Figure 5 from close to the surface to the BM, are collated for the four specimens in Figure 6. The hardness of the BM steel was $\sim 150 \mathrm{Hv}$, which after TIG processing increased to between 220 and $270 \mathrm{Hv}$. Those specimens with $\mathrm{SiC}$ additions processed at 420 and $840 \mathrm{Jmm}^{-1}$ showed substantial increases in hardness to 800-900 Hv, retained for a meltzone depth $>1 \mathrm{~mm}$. Optical Macrographs (OM) of two cross-sections taken from samples at 225 $\mathrm{mm}$ along the track are shown in Figure 6. Following TIG processing at $420 \mathrm{Jmm}^{-1}$, the sample with $\sim 75 \mu \mathrm{m} \mathrm{SiC} \mathrm{particulates} \mathrm{shows} \mathrm{no} \mathrm{cracks,}$ Figure 6(a), while the cross-section of the track processed using $840 \mathrm{Jmm}^{-1}$, Figure 6(b) shows a significant crack, which also occurred for the samples prepared with $\sim 5 \mu \mathrm{m} \mathrm{SiC} \mathrm{powder} \mathrm{at} \mathrm{this}$ energy input. Despite the greater MZ volume produced using $840 \mathrm{Jmm}^{-1}$, it was decided to confine subsequent processing to an energy input of $420 \mathrm{Jmm}^{-1}$. XRD spectra were recorded for the TIG processed rough MZ surface of the MA steel samples incorporating $\sim 5$ or $\sim 75 \mu \mathrm{m} \mathrm{SiC}$ particulates taken between thermocouples 1 and 2 , to study the phases developed as a function of particulate size. Following $840 \mathrm{Jmm}^{-1}$ processing, analytical scanning electron microscopy indicated high sulphur contents on the surfaces of the cracks, suggesting a dissolution of $\mathrm{MnS}$ particles giving brittle FeS layers.
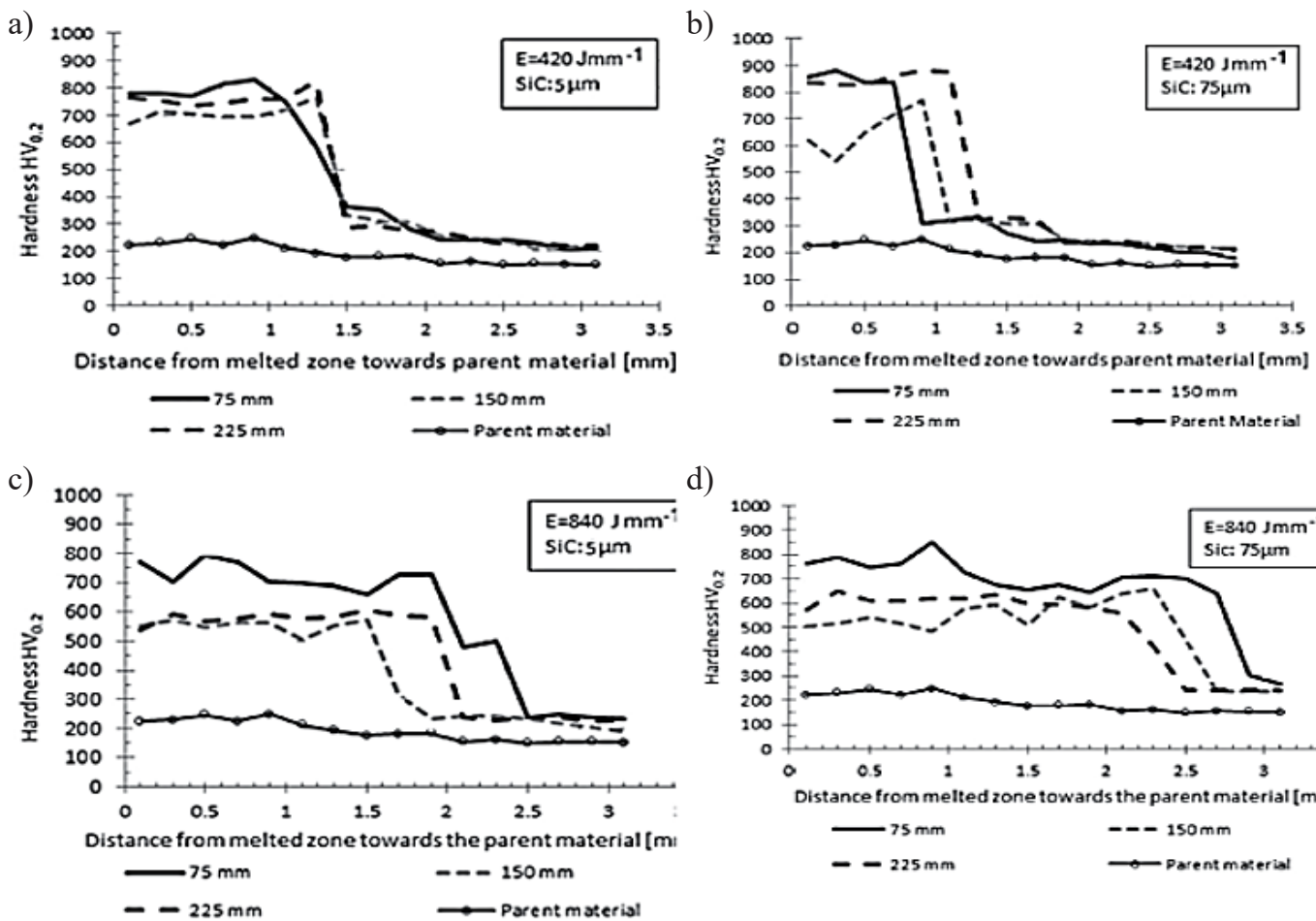

d)

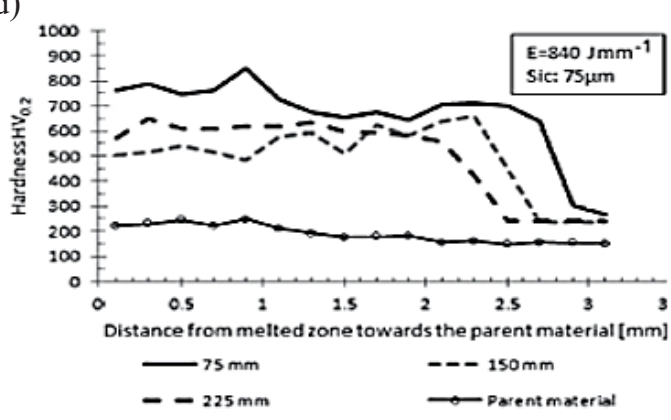

Fig. 5. Hardness profiles of cross-sectional areas at 75,150 and $225 \mathrm{~mm}$ from the start of the track, a) $420 \mathrm{Jmm}^{-1}(\sim 5 \mu \mathrm{m})$, b) $420 \mathrm{Jmm}^{-1}(\sim 75 \mu \mathrm{m})$, c) $840 \mathrm{Jmm}^{-1}(\sim 5 \mu \mathrm{m})$, d) $840 \mathrm{Jmm}^{-1}(\sim 75 \mu \mathrm{m})$ 

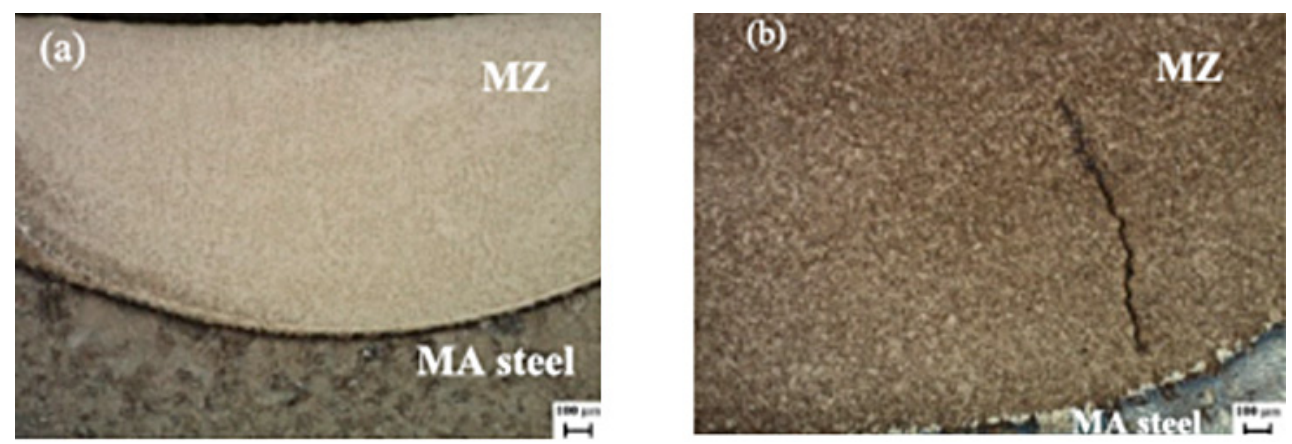

Fig. 6. Optical micrographs of MZ and BM of the MA steel following TIG processing of preplaced $\sim 75 \mu \mathrm{m} \mathrm{SiC} \mathrm{particulates} \mathrm{using} \mathrm{two} \mathrm{energy} \mathrm{inputs,} \mathrm{a)} 420 \mathrm{Jmm}^{-1}$ and b) $840 \mathrm{Jmm}^{-1}$

The XRD spectrum in Figure 7(a), collected from the MA steel incorporating $\sim 5 \mu \mathrm{m} \mathrm{SiC} \mathrm{par-}$ ticulates, shows peaks related to martensite, silicon dioxide, cementite (Cohenite, $\mathrm{Fe}_{3} \mathrm{C}$ ) and iron silicide $\left(\mathrm{DO}_{3}, \mathrm{Fe}_{3} \mathrm{Si}\right)$. With the exception of the austenite peaks, and with the addition of peaks corresponding to graphite, the $\sim 75 \mu \mathrm{m} \mathrm{SiC} \mathrm{MA}$ steel spectrum contains the same peaks. Also in Figure 7(a), spectra are included from the $\sim 75$ $\mu \mathrm{m} \mathrm{SiC} \mathrm{powder} \mathrm{used} \mathrm{in} \mathrm{this} \mathrm{work} \mathrm{and} \mathrm{from} \mathrm{the}$ BM. The strongest peaks excited by the $\sim 75 \mu \mathrm{m}$ $\mathrm{SiC}$ powder are indicated at $2 \theta$ values of $\sim 35^{\circ}$. However, it is apparent that there is insufficient matching between the $\mathrm{SiC}$ peaks in the spectrum from the powder alone and the spectra from the TIG processed MA steel/SiC specimens to claim that $\mathrm{SiC}$ is present in these latter spectra. SEM showed that a needle shaped phase Figure 7(b), often surrounded by a boundary was observed in the transverse section taken close to the start of section 2 seen in Figure 1(a). In agreement with the XRD spectra in Figure 7(a), following TIG processing, the EDX analysis showed Si levels too low to identify a $\mathrm{SiC}$ phase. Also, C levels of $\sim 3.5$ wt.\% were recorded in the needle areas, Figure 7(b), strongly suggesting that the dissolution of the $\mathrm{SiC}$ particulates resulted in the formation of a high carbon martensite, which is considered to be a factor in the increase in hardness seen in the graphs in Figure 5 [33].

Several attempts have been made to prevent the dissolution or partial dissolution of $\mathrm{SiC}$ particulates in iron and steels, but with little success [37, 38] as unprotected $\mathrm{SiC}$ also reacts readily with iron in the solid state at 1000-1200 ${ }^{\circ} \mathrm{C}(1273-1373 \mathrm{~K})$. Research on the Fe-Si-C system by Kawanishi et al. [39] suggests that a high Si content could decrease SiC dissolution in liquid iron. This was developed further by Baker et al. [34], who placed layer of silicon particulates next to an MA steel specimen, with the intention of forming a high $\mathrm{Fe}-\mathrm{Si}-\mathrm{C}$ liquid a)

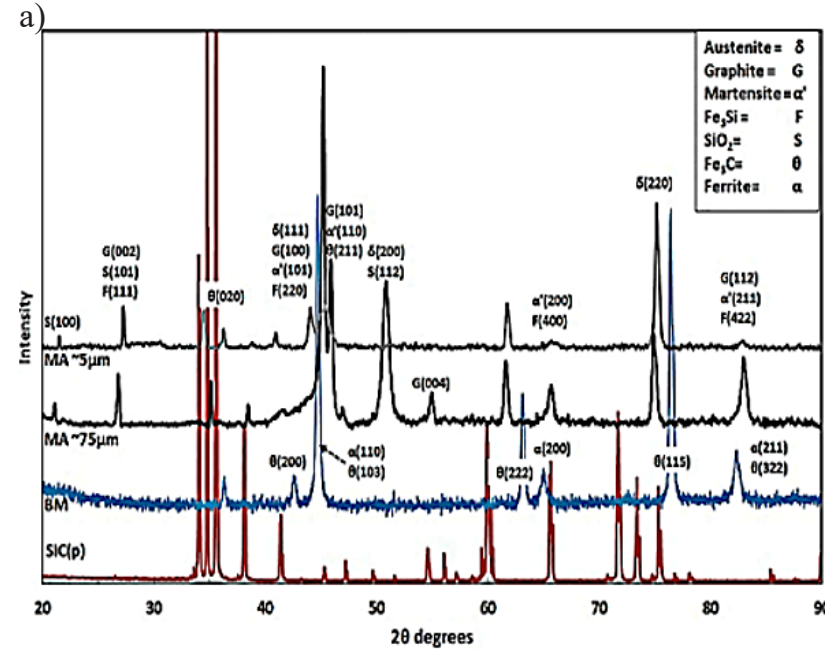

b)

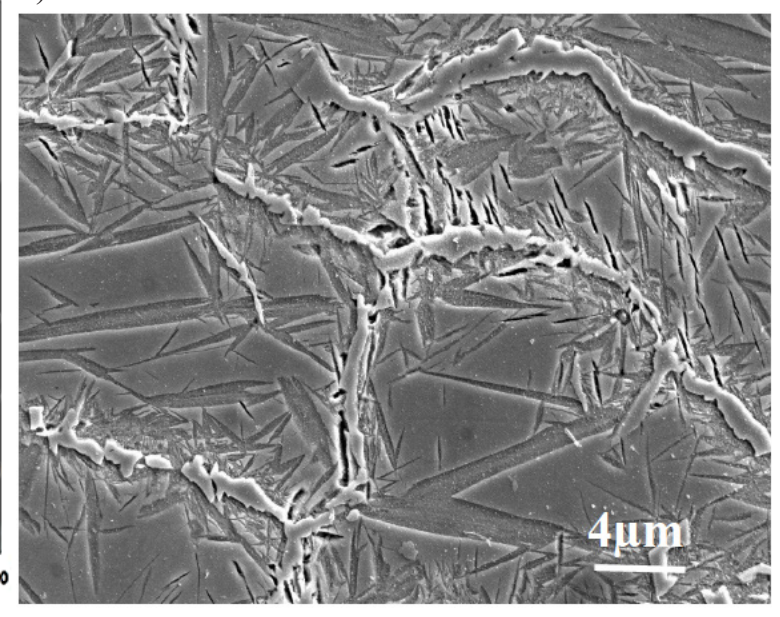

Fig. 7. a) XRD spectra of $\sim 75 \mu \mathrm{m} \mathrm{SiC(p),} \mathrm{BM} \mathrm{and} \mathrm{MA} \mathrm{steels} \mathrm{with} \sim 5 \mu \mathrm{m} \mathrm{SiC}$ and $\sim 75 \mu \mathrm{m} \mathrm{SiC}$, b) SEM micrograph of $\sim 75 \mu \mathrm{m} \mathrm{MZ}$ top surface 


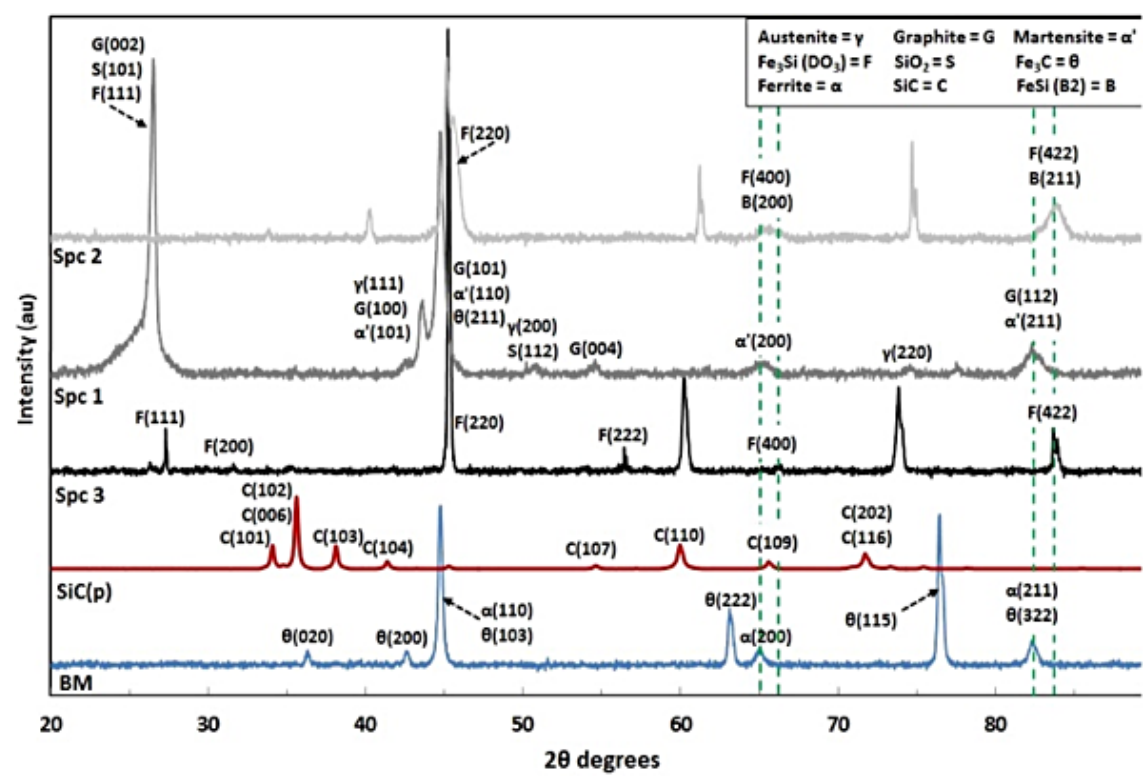

Fig. 8. XRD spectra of Specimens 1,2 and 3, SiC powder and the BM MA steel

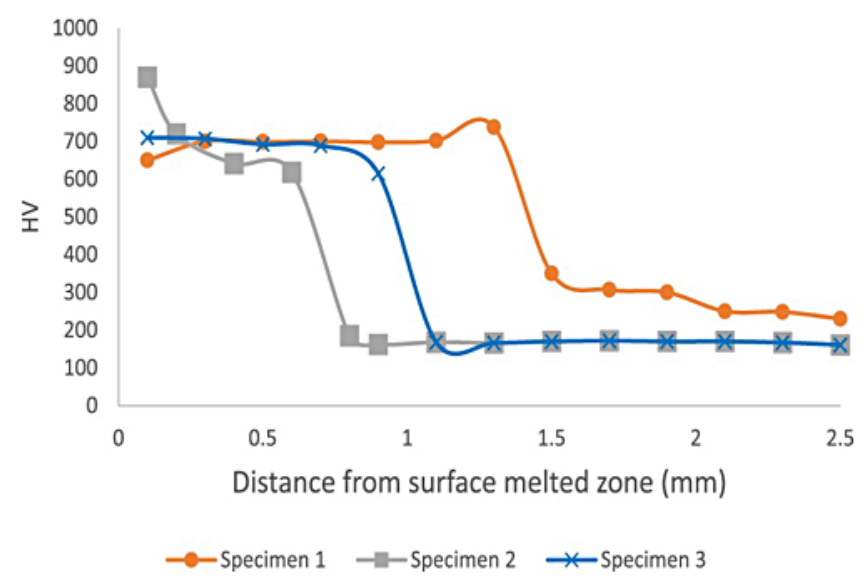

Fig. 9. Hardness $v$ distance from the surface MZ for the three specimens

phase, before a second layer comprised of $\sim 5$ $\mu \mathrm{m} \mathrm{SiC} \mathrm{particulates} \mathrm{was} \mathrm{incorporated} \mathrm{into} \mathrm{the}$ melt. An energy input of $420 \mathrm{Jmm}^{-1}$ was used, selected as the optimum in a previous project [33] for achieving a high hardness to a depth $>1$ $\mathrm{mm}$ without porosity or cracking. The X-ray specta in Figure 8 were recorded from Specimen 1, (SiC), Specimen 2, $(\sim 45 \mu \mathrm{m}$ Si particulates placed on the $\mathrm{BM}$, dried, then $\mathrm{SiC}$ preplaced on the Si coated steel specimen), while Specimen 3 was a Si coated steel, then TIG processed [34].

In Figure 8, Specimens $2(\mathrm{Si}+5 \mu \mathrm{mSiC})$ and $3 \sim(45 \mu \mathrm{m}$ Si alone $)$, both show peaks indicating the $\mathrm{FeSi}_{3}$ phase which occurs at $\sim 23 \mathrm{wt} . \% \mathrm{Si}$ in the $\mathrm{Fe}-\mathrm{Si}$ equilibrium diagram [40]. Specimen 1(SiC alone) shows no peaks corresponding to Fe${ }_{3} \mathrm{Si}$, but strong peaks corresponding to $\mathrm{FeSi}$. This phase occurs at lower Si levels of 5-15wt.\%, and indicates that lower Si levels which might protect the $\mathrm{SiC}$ from dissolution and avoid the more brittle $\mathrm{DO}_{3} \mathrm{Fe}_{3} \mathrm{Si}$ phase, which is considered to be associated with the fine cracking recorded in the functionally graded MZ of Specimens 2 and 3. Microhardness data in Figure 9, shows that Specimen 2 has a maximum of $880 \mathrm{Hv}$ at $\sim 0.1 \mathrm{~mm}$ in $\mathrm{MZ}$, while Specimens 2, and 3 have maximum of $\sim 700 \mathrm{Hv}$ retained to $>1 \mathrm{~mm}$ depth.

Microstructural analysis was undertaken on the three TIG processed specimens. Figure 10 is an optical micrograph showing the MZ separated into two layers, the upper layer A containing larger particulates, while they are absent in the lower layer B. EDX analysis given in Table 3 of several phases arrowed in Figure 11, indicates that both 
particles 1 and 3 are mainly $\mathrm{SiC}$ (stoichiometric $\mathrm{Si} / \mathrm{C}=2.33$ ), while 2 is predominantly graphite. 4 and 5 may be based on $\mathrm{Fe}_{3} \mathrm{Si}$, detected in the XRD spectrum in Figure 8. The absence in Figure 8 of $\mathrm{SiC}$ peaks maybe due to the relatively small volume fraction sampled in layer A.

Fine cracks were observed close to the surface of the MZ in Specimen 2, and also reported by Liang et al. [41] who claimed that the cracks were due to a matrix of $\mathrm{DO}_{3} \mathrm{Fe}_{3} \mathrm{Si}$, which was also identified in XRD Spectra in Figures 7 and 8.

Reducing the $\mathrm{Si}$ level from 20.31wt.\%, Table 3, to produce an MZ Si level of $\sim 5.0$ wt. $\%$,accompanied by rapid cooling, may result in the development of a matrix of the less brittle B2FeSi phase, and eliminate cracking.

The application of TIG as an economic process for surface engineering is now well established [42].

Successful surface engineering based on laser or TIG processing should use an energy input that is sufficient to melt the base metal, thus allowing the ceramic particulate to be incorporated into the MZ, but normally insufficient energy to completely melt the ceramic. Also, porosity and cracking, which have been reported in some work, must be avoided $[22,33]$. A wide range of energy inputs (E) from 210 to $3479 \mathrm{Jmm}^{-1}$ have been investigated [23-27].

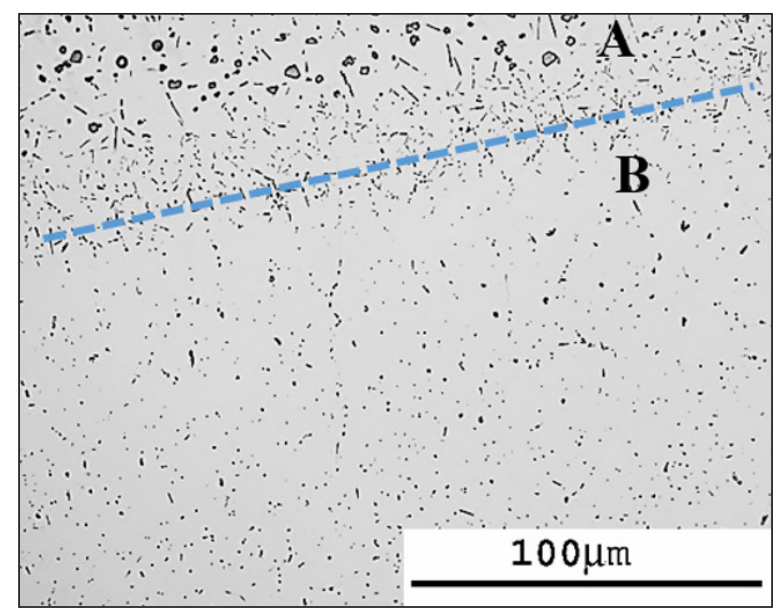

Fig. 10. Specimen 2 OM showing two layers
It has been shown $[29,31]$ that the choice of protective shielding gas has a significant influence on the preheat generated during the TIG processing of an area by melting a series of overlapping tracks, Fig. 3(a), but also between the start and end of a single track, Fig. 3(b). This can lead to a varying microstructure, and hence properties, along the length of a track. To reduce this effect in the case of the processing of an area, different patterns of melting tracks have been adopted [35]. This problem has also been addressed for the same reasons in $3 \mathrm{D}$ printing [43].

\section{CONCLUSIONS}

The application of TIG as an economic process for surface engineering is now well established. The present work has shown that the influence of input energy and shielding gas can increase the melt zone hardness by $>800 \mathrm{Hv}$ in low alloy steels through incorporation of $\mathrm{TiC}$, and in microalloyed steels through incorporation of $\mathrm{SiC}$ particulates, The hardness depends on the melt track position from which it is determined. This is

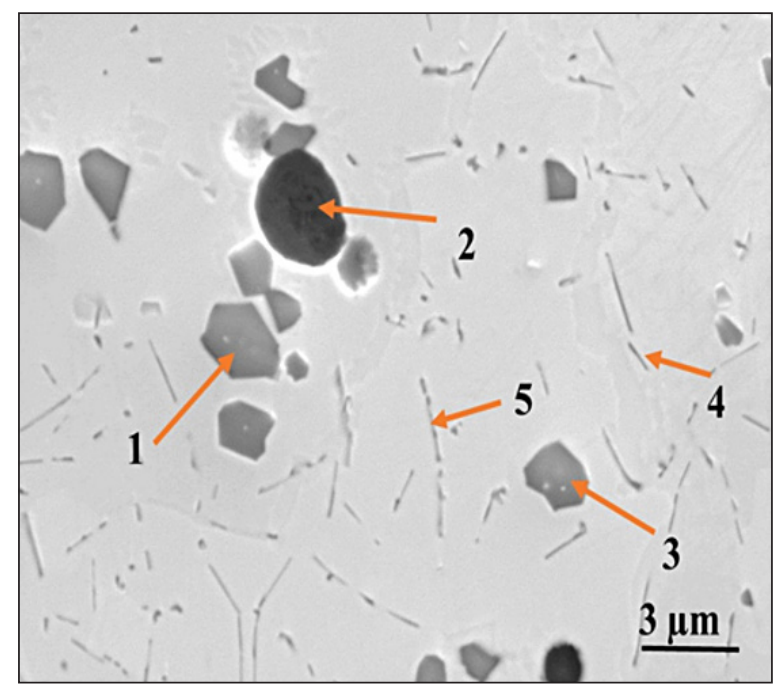

Fig. 11. Specimen 2 SEM showing five arrowed precipitates

Table 3. Specimen 2 EDX compositional data for positions arrowed in Figure 11

\begin{tabular}{|c|c|c|c|c|c|c|}
\hline Spectrum & $\mathrm{C}$ & $\mathrm{O}$ & $\mathrm{Si}$ & $\mathrm{Mn}$ & $\mathrm{Fe}$ & Si/C \\
\hline 1 & 33.57 & & 61.23 & & 5.21 & 2.19 \\
\hline 2 & 87.03 & 2.80 & & 1.41 & 8.76 & \\
\hline 3 & 35.44 & & 59.52 & & 5.04 & 1.93 \\
\hline 4 & 4.82 & & 20.31 & 0.92 & 73.95 & \\
\hline 5 & 11.76 & & 24.93 & 0.62 & 62.70 & \\
\hline
\end{tabular}


due primarily to the increase in temperature (preheat) noted along a single track, or in different tracks when treating an area. The partial or complete particulate dissolution leading to the formation of new phases also has been a major factor in determining hardness over the volume of the melt zone track. This is particularly the case for the incorporation of $\mathrm{SiC}$ particulates. The possibility of avoiding the dissolution of $\mathrm{SiC}$ in steels during TIG processing, is offered a possible solution through the development of a high Fe-Si liquid phase. However, the formation of brittle $\mathrm{DO}_{3}$ $\mathrm{Fe}_{3} \mathrm{Si}$ phase must be avoided.

\section{Acknowledgements}

The authors would like to acknowledge that some of this work was carried out at the Advanced Materials Research Laboratory, housed within the University of Strathclyde.

\section{REFERENCES}

1. Ettmayer P. Hardmetals and Cermets. Annual Review of Materials Science 1989; 19: 145-164.

2. Jaworska L, Rozmus M, Królicka B, Twardowska A.Functionally graded cermets. J. Achiev. Mater. Manuf. Eng., 2006;17 (1-2):73-76.

3. Barsoum MW, Radovic M. MAX phases: bridging the gap between metals and ceramics. Am Ceram Soc Bull. 2013;92(3): 20-27.

4. Muñoz de Escalona P, Lees C, Sillars F, Mridha $\mathrm{S}$, Baker TN. Development of a metal matrix composite layer on a microalloyed steel surface by dissociating MAX211 Ti2AlC particles using a TIG torch technique. Adv Mater Proc Technol. 2017;3(4):586-599.

5. Song Y, Baker TN. Accelerated aging processes in ceramic reinforced AA-6061 composites. Mater Sci Technol. 1994;10 (5):406-413.

6. Gurcan AB, Baker TN. Wear behavior of AA6061 aluminum-alloy and its composites.'Wear 1995;188 (1/2:)185-191.

7. Zhang, BL; Maclean, MS; Baker, TN. Hot deformation behaviour of aluminium alloy 6061/SiCp MMCs made by powder metallurgy route. Mater Sci Technol. 2000;16(7-8):8997-902.

8. Baker TN, Xin H, Hu C, Mridha S. Design of surface in-situ metal-ceramic composite formation via laser treatment. Mater Sci Technol. 1994;10(6): 536-544.

9. $\mathrm{Hu} \mathrm{C}, \mathrm{Xin} \mathrm{H}, \mathrm{Baker}, \mathrm{TN}$. Laser processing of an aluminium AA6061 alloy involving injection of SiC particulate. J Mater. Sci.1995; 30 (23):5985-5990.
10. Hu C, Baker, TN. Laser processing to create in-situ Al-SiCp surface metal-matrix composites. J Mater Sci.1995;30 (3): 891-897.

11. Hu C, Xin H, Baker TN. Formation of continuous surface Al-SiCp metal matrix composite by overlapping laser tracks on AA6061 alloy. Mater Sci Technol. 1996; 12 (3) :227-232.

12. Hu C, Baker, TN A new aluminium silicon carbide formed in laser processing.' J Mater Sci.1997;32 (19):1997.

13. Mridha S, Baker TN. Metal matrix composite layer formation with $3 \mathrm{mu} \mathrm{SiCp}$ powder on IMI318 titanium alloy surfaces through laser treatment.J.Mater. Proc.Technol.1997;63 (5) :432-437.

14. Mridha S, Baker TN Metal matrix composite layers formed by laser processing of commercial purity Ti-SiCp in nitrogen environment. Mater Sci Technol. 1996;12 (3) :595-602

15. Mridha S, Ubhi HS, Holdway P, Baker T N, Bowen A W. Metal-ceramic composite layer formation on titanium surfaces through laser treatment, in: F.H. Froes, I.L. Caplan (Eds.), Proceedings of the Titanium'92, TMS, Warrendale, p. 2641. 1996 227-232.

16. Baker T N. Laser surface modification of titanium alloys. Surface engineering of light alloys: aluminium, magnesium and titanium alloys. Woodhead Publishing in Materials, 2010,398-443.

17. Ayers JD, Tucker TR, Particulate-TiC-hardened steel surfaces by laser melt injection!. Thin Solid Films.1980; 73:201-207.

18. Abboud J H, West DRF Ceramic-metal composites produced by laser treatment. Mater. Sci. Technol., 1989; 51 (7):725-728.

19. Bergmann HW, Mordike BL. Structure of laser melted steel surface. Zeitschrif fur Metall.1980;71:658-665.

20. Bell T, Morton PH, Bloyce A. Towards the design of dynamically loaded titanium engineering components. Mater. Sci. Eng. A, 1994; A184 (2): 73-86.

21. Atamert S, Bhadeshia HKDH. Comparison of the microstructures and abrasive wear properties of stellite hardfacing alloys deposited by arc-welding and laser cladding Metall. Trans. A, 1989;20A:1037-1054.

22. Khan TI, Fowles D. Surface modification of tool steel using tungsten arc heat source. Surf. Eng., 1997; 13: 257-259.

23. Mridha $\mathrm{S}, \mathrm{Ng}$ BS. Addition of ceramic particles to TIG melted titanium surfaces. Surf. Eng. 1999; 15: 210-215.

24. Wang XH,Zhang M, Zou ZD, Song SL, Han F, Qua $\mathrm{SY}$. In situ production of Fe-TiC surface composite coatings by tungsten-inert gas heat source. Surf. Coat. Technol.2006;200: 6117-6122.

25. Paraye NK, Neog SP, Ghosh PK, Das S. Surface modification of AISI 8620 steel by in-situ grown 
TiC particle using TIG arcing. Surf Coat Technol.2021; 405:126533.

26. Patel P, Mridha S, Baker TN. Influence of shielding gases on preheat produced in surface coatings incorporating $\mathrm{SiC}$ particulates into microalloy steel using TIG technique. Mater Sci Technol. 2014; 30(12):1506-1514.

27. Mridha S, Baker TN. Overlapping tracks processed by TIG melting TiC preplaced powder on low alloy steel surfaces. Mater Sci Technol. 2015; 31(3):337-343.

28. Mridha S., Idriss A N Md, Maleque M A, Yaacob II, Baker TN. Melting of multipass surface tracks in steel incorporating titanium carbide powder. Mater Sci Technol. 2015; 30(11):1362-1369.

29. Muñoz de Escalona P, Mridha S, Baker TN. Effect of shielding gas on the properties and microstructure of a melted steel surface by a TIG torch. Adv Mater Proc Technol. 2015;1:435-443.

30. Muñoz de Escalona P, Mridha S, Baker TN. Effect of silicon carbide particle size on the microstructure and properties of a coating layer on steel produced by TIG technique. Adv Mater Proc Technol. 2016; 2:451-460.

31. Muñoz de Escalona P, Mridha S, Baker TN. Effect of shielding gas and energy input on the surface geometry and microstructure of a microalloyed steel surface melted steel with a TIG torch. Adv Mater Proc Technol. 2017; 3:550-562.

32. Muñoz de Escalona P, Walker A, Ogwu A, Mridha $\mathrm{S}$, Baker $\mathrm{T}$ N. Comparison of empirical and predicted substrate temperature during surface melting of microalloyed steel using TIG technique and considering three shielding gases. Appl.Surf. Sci.2019;477:179-183.

33. Muñoz de Escalona P, Sillars F, Morrocco T, Edgar R, Mridha S, Baker T N. Silicon carbide particles incorporated into microalloyed steel surface: microstructure and properties. Mater Sci Technol. 2020; 36 (1):17-32.

34. Baker T N, Muñoz-de Escalona P, Olasolo M, Marrocco T, Kelly J, Wei B, He K, Mridha S. Role of preplaced silicon on a TIG processed SiC incorporated microalloyed steel. Mater.Sci.Technol.2020; 36 (12): 1349-1363.

35. Hu C, Baker TN. The importance of preheat before laser nitriding a Ti-6Al-4V alloy. Mater Sci Eng A. 1999;265: 268-275.

36. Rosenthal D, Mathematical theory of heat distribution in welding and cutting. Weld J,1941;20:220-234.

37. Majumdar JD, Chandraa BR, Nath AK, et al. Studies on compositionally graded silicon carbide dispersed composite surface on mild steel developed by laser surface cladding. J Mater Process Technol. 2008;203: 505-512.

38. Tang WM, ZhengZX, DingHF, et al. A study of the solid state reaction between silicon carbide and iron. Mater Chem Phys. 2002; 74(2): 58-264.

39. Kawanishi S, Yoshikawa T , Tanaka T. Equilibrium phase relationship between $\mathrm{SiC}$ and a liquid phase in the Fe-Si-C system at 1523-1723K. Mater Trans. 2009; 50:806-813.

40. Kubaschawski O. Iron-binary phase diagrams. New York (NY): Springer-Verlag; 1982.

41. Liang YF, Lin JP, Ye F, Li YJ, Wang YL, Chen GL. Microstructure and mechanical properties of rapidly quenched $\mathrm{Fe}-6.5 \mathrm{wt} . \% \mathrm{Si}$ alloy. J Alloys Compds.2010;504S: S476-S479.

42. Azwan M, Maleque M A, Rahman M M. TIG torch surfacing of metallic materials - a critical review. Trans. Inst. Metal Finish.2019;97: 12-21.

43. Su X, Yang Y. Research on track overlapping during Selective Laser Melting of powders .J Mater Proc.Technol. 2012;212:2074-2079. 